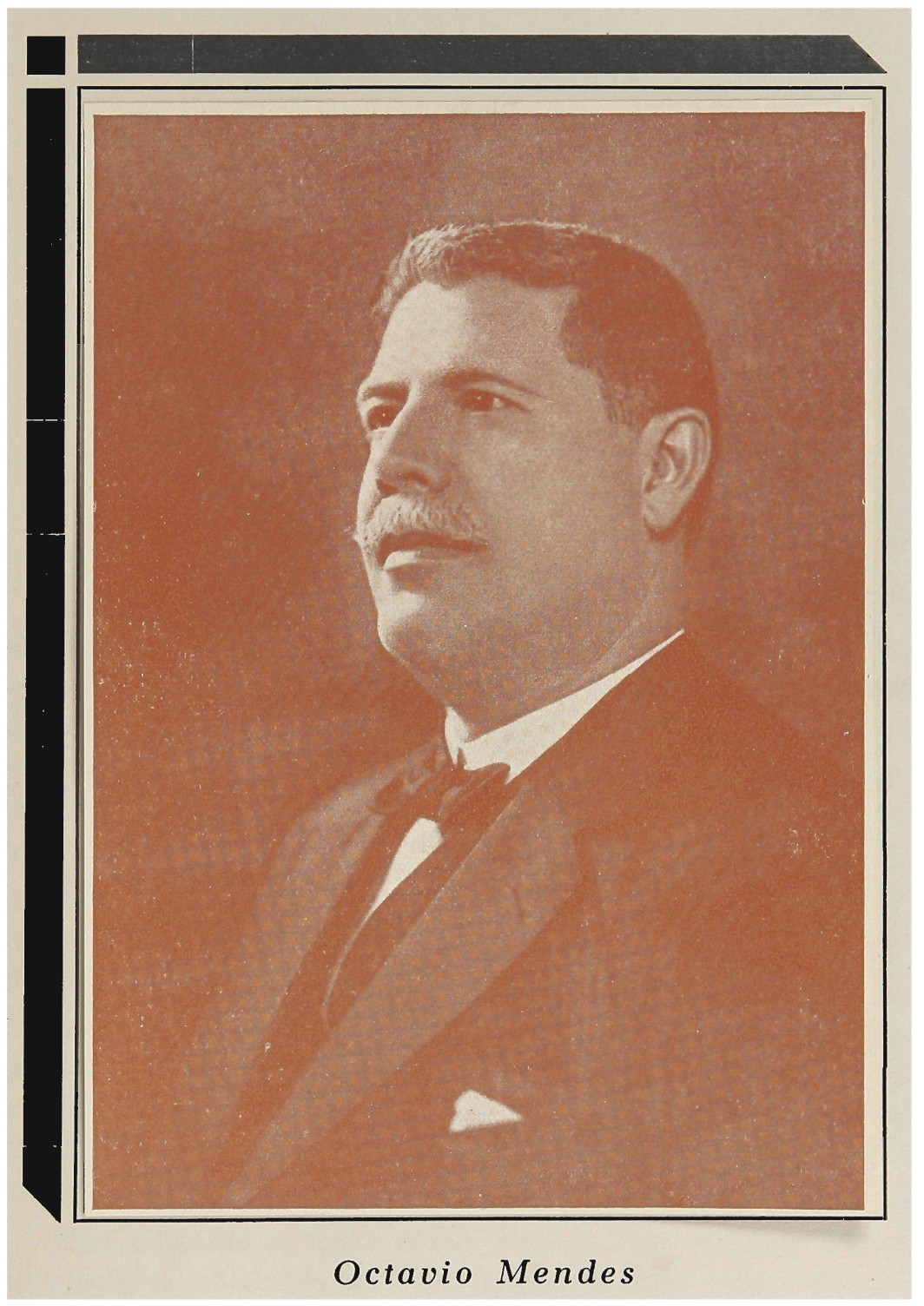




\section{Octavio Mendes}

Nasceu Octavio Mendes em Campinas, na provincia de São Paulo, aos 12 de abril de 1869 . Foram seus pais o major Manoel Francisco Mendes e D. Leopoldina da Cunha Mendes. Estudou as primeiras letras em suas terra natal, fazendo, com brilhantismo, o curso do Colegio Culto á Ciencia, de tanto renome ao seu tempo e posteriormente, ao depois transformado no Ginasio de Campinas. Prestou os seus exames parcelados no antigo Curso Anexo á Faculdade de Direito de São Paulo, na qual iniciou o seu curso juridico em 1885.

De familia pobre, viu-se na contingencia de trabalhar na Provincia de São Paulo, afim de poder proseguir nos seus estudos. "Trabalhava de noite", dizia ele, "para poder me manter e completar meu curso, porque meus pais eram pobres".

Não obstante o rigor então vigente nos exames, conseguiu sempre notas plenas. Pertencera a uma turma de que fizeram parte, entre outros, João Luiz Alves, Carlos Peixoto Filho, Herculano de Freitas, Paulo Prado, Affonso Arinos, Affonso de Carvalho, Edmundo Lins, Mendes Pimentel. 
Recebeu o grau de bacharel em ciencias juridicas e sociais em 5 de novembro de 1889 , poucos dias antes da proclamação da Republica. Conservou, porém, a sua convicção monarquista, embora dela não fizesse manifestação publica, a não ser uma unica vês, em aula, ao relembrar, com saudade, o prestigio do Brasil durante o Imperio. Em familia e com os seus intimos era comum ouvi-lo repetir ser bacharel da Monarquia.

Formado, foi, entretanto, o primeiro procurador da Republica em São Paulo, em 1890; mas poucos mêses permaneceu no cargo. Fotografou-o nessa epoca Max Fleiuss, em interessantissima pagina de recordações, publicada no Jornal do Comercio, do Rio de Janeiro, dias depois de seu falecimento:

"Quando foi do enterro de Esmeraldino Bandeira, tive ligeira palestra com J. X. Carvalho de Mendonça.

Tratamos do morto e depois, no desenvolver do assunto, dos grandes especialistas da ciencia do Direito.

As palavras de Carvalho de Mendonça esboçavam com segurança varios perfis e, quando chegou a vez dos comercialistas, disse-me:

- "Para mim, o maior é Octavio Mendes... Que clareza na expressão! que amplitude de raciocinio..."

Sorri; Carvalho de Mendonça interpelou-me.

- Octavio Mendes, respondi, é um dos meus velhos amigos, dos mais intimos!

De fáto, conhecemo-nos na redação da Provincia de São Paulo, onde, na época, pontificava o grande espirito de Rangel Pestana.

Daí nossas relações se estreitaram.

Logo depois de formado, veio passar comigo quinze dias, em minha casa do Cosme Velho. Recebido pelos meus como se fôra da familia, fez-se querido.

Era um joven de vinte anos; muito alegre, inteligente, estudioso, com decidida inclinação pela musica, predicado que, talvez, lhe adviera do proximo parentesco com Carlos Gomes. 
Surge a Republica. Octavio Mendes é nomeado procurador seccional em S. Paulo, ponto de partida para os mais elevados cargos da magistratura, se não houvesse preferido abandonar a carreira para fixar-se como advogado.

Ainda procurador, apaixonou-se. Vem de novo para a minha casa, então á rua do Rezende, de onde, em certa manhã, sae com Francisco Glicerio e comigo para a cerimonia nupcial.

Campos Salles devia ser o padrinho; não lhe fôra, entretanto, possivel vir do Banharão. Gucerio representava-o.

Quando ficou noivo, escreveu-me uma carta que lhe reflete o coração:

"Advinhaste, querido amigo! No dia 24 do mês passado tratei o meu casamento.

"Sinto-me feliz, enormemente feliz, pois vejo realizado o mais belo sonho de minha vida, em que já pensava ha muito tempo, mas do qual desesperei sempre.

"Tienho vontade de abraçar a todo mundo, pelo que calculará a efusão sincera do abraço que te envio nesta carta".

Depois, quando veio para o casamento, mandou-me outra carta:

"Parto depois de amanhã (domingo) para aí; e por motivos que facilmente compreenderás, não quero ir para a casa de meus futuros sogros. Por isso te incomodo mais esta vez, pedindo-lhe hospitalidade, mesmo porque receio que eles saibam de minha viagem e estejam na estação á minha espera. Por isso conto com a tua velha amizade, para me servir nesta conjuntura".

Desde o tirocinio academico se revelára o futuro triunfador. E, a principio parecia especializar-se no Direito Criminal, pois foram seus primeiros trabalhos traduções de Puglia sobre A tentativa, Prolegomenos ao estudo de direito repressivo; Legitimx defesa, de FIoretri; Nova Escola Penal, de Lroz. 
Mais tarde vieram as obras do comercialista, em que se tornou insigne, o que provam as palavras de CarvalHo DF MendonçA.

Doente, gravemente, nem por isso deixou de competir no concurso para o magisterio na gloriosa Faculdade de S. Paulo.

Ei-lo professor. Suas aulas merecem a atenção geral. Mestres e discipulos acodem e aplaudem o novo docente que, não obstante sempre enfermo, não se podendo quasi mover, é de absoluta pontualidade na Faculdade e no movimentado escritorio.

Não fôra a molestia e teria atingido ás culminancias da vida publica.

Merecia-o pelo extremoso coração e pela esbeltez do espirito.

Sua memoria será a reliquia dos que lhe formavam a familia.

Será tambem a dos amigos que por tantos anos sempre o acompanharam.

E quando desaparecerem - uns e outros - restará um fator para lhe assegurar o renome: a historia do nosso Direito".

Eis, em frases de mais afetuosa homenajem, os caminhos de sua vida. Abandonando a procuradoria da Republica, transferiu-se para Campinas, nomeado promotor publico, cargo em que manifestou os seus pendores pelos estudos de direito criminal. Deixou, pouco tempo depois, esse cargo, por ter sido nomeado, em 1893, juiz de direito da comarca de Sorocaba, no Estado de São Paulo, onde proferiu a sua primeina sentença aos 14 de janeiro daquele ano. O seu temperamento impetuoso não condizia com o socego da vida do magistrado provinciano. Por isso, em 1895, abandonou, tambem, a magistratura e transportou-se para São Paulo, onde instalou o seu escritorio de advocacia.

Ganhou, então, grande nomeada. Trabalhador infatigavel, multiplicou a sua atividade e o seu escritorio veiu a ser um dos mais procurados. Advogado era e nesse minis- 
terio permaneceu. Não o seduziu a politica, para a qual quiz, muitas vezes, dar-lhe ingresso seu sogro, MANuEL DE Moraes Barros, senador paulista no Congresso Nacional e real influencia pelos seus nobres meritos.

Não obstante, fundado o Partido Democratico de São Paulo, a ele aderiu ultimamente, acompanhando, com o mais vivo interesse, o desdobrar dos acontecimentos politicos. Diante da intervenção do presidente Washingron Luis, indebitamente, no Estado da Paraíba, formulou, em aula, perante seus alunos do terceiro ano, o mais veemente protesto, expresso em telegrama ao presidente da Republica, contra o sacrificio daquele Estado, ao mesmo tempo em que enviava valoroso aplauso á atitude do seu presidente JoÃo PessôA.

Acometeu-o, em 30 de janeiro de 1910, pertinás molestia, que o prostrou de cama quasi um ano. Ao levantar-se, falharam-lhe as pernas, atacadas de paralisia. Em busca de melhoras, seguiu para a Europa, de onde regressou, em dezembro de 1912, quasi no mesmo estado. Instado por seu cunhado, Antonio de Moraes Barros - seu companheiro de escritorio e grande advogado, ha pouco falecido, nome nesta pagina relembrado com a mais viva emoção, pelas suas altas qualidades, que lhe deram tão alto destaque na vida social, politica e forense de São Paulo - tornou Octavio MenDES ao seu posto de advogado. Reiniciou a sua faina, somente tres vêses interrompida: em 1920, para preparar-se para o concurso que lhe deu a catedra da Faculdade de Direito; em 1925, quando empreendeu nova viajem á Europa, em busca de melhoras para o seu estado de saude; e em 1931, quando foi da molestia que o levou.

A paralisia dos membros inferiores não o impedia de trabalhar. Comparecia, diariamente, ao seu escritorio, na cidade; e os que, então, com ele tratavam, vendo-o na sua poltrona, mal podiam compreender o seu sofrimento fisico, que o busto forte e a fisionomia larga e vivás encobriam.

Ainda assim, concorreu á vaga aberta pelo falecimento de Brasilio Machado e o acesso de Frederico Vergueiro 
Steidel na cadeira de direito comercial da Faculdade de Direito de São Paulo. Teve como competidores Waldemar Martins Ferreira e Plinio Balmaceda Cardoso. Classificado em primeiro lugar, foi nomeado professor substituto em 8 de junho de 1920 e catedratico pelo falecimento de Gabriel de Rezende, em 18 de agosto de 1923. Exerceu o magisterio juridico ininterruptamente quasi. Era dos professores mais assiduos, sem embargo de ser transportado para a sala de aula em uma cadeira. Não subia, por isso, á catedra. Ao lado dela existia uma mesa, da qual procedia á leitura de suas preleções, impressas em volumes pouco antes de sua morte. Constam elas dos seus dois livros, que tanta aceitação tiveram no mundo juridico brasileiro, sendo constantemente citados em sentenças e acórdãos: o Direito Comercial Terrestre e o de Falencias e Concordatas.

Seu metodo de ensino consistia em ilustrar suas preleções com narrativas de casos de sua vida profissional e submeter seus alunos a trabalhos praticos, exercitando-os em assembléas de credores, impugnações de creditos, etc.

O seu ultimo livro publicado foi o sobre Titulos de Credito, em 1931, editado pela Livraria Academica, de Saraiva \& Cia., de São Paulo.

Convidado pelo presidente do Estado de São Paulo a elaborar a critica, que em nome dele seria apresentada, ao projecto do codigo comercial de INGLEZ DE SouzA, apresentou-lhe o seu trabalho, em 1915, incorporado aos da Comissão Especial do Codigo Comercial do Senado, um dos poucos que the foram oferecidos.

Faleceu no dia 12 de novembro de 1931, após cinco meses de inauditos sofrimentos, suportados com o mesmo estoicismo com que suportou a paralisia durante vinte e dois anos.

O seu enterro foi a demonstração eloquente do apreço em que o tinham a sociedade paulista e os seus colegas e alunos da Faculdade de Direito. O seu caixão foi conduzido da camara ardente, no seu palacete da Avenida Paulista, para o coche, pelos seus colegas da Congregação, em nome 
da qual proferiu o professor SPENcER VAMPRÉ, ao baixar á sepultura, no cemiterio da Consolação, este discurso:

"Manda-me a Faculdade de Direito de S. Paulo, de que o doutor Octavio Mendes foi um dos mais ilustres professores, trazer-lhe, nesta hora pesarosa para os seus amigos e para o Brasil, a expressão de sua comovida saudade, ao companheiro de todos os dias, ao mestre querido de sua mocidade.

Mestre ele o foi, pela dedicação indefesa, pelo trato amoravel aos colegas e aos discipulos, pela paixão irreprimida dos estudos doutrinarios, pela assiduidade sem par, e pelo carinho com que guardava as tradições e as glorias da velha casa de ensino, que se orgulha de havel-o contado entre os seus docentes.

Mestre o foi, por essas lições diuturnas de amor ao trabalho, por esse heroismo silencioso, mas formidavel, que o fazia esquecer as dôres físicas para emparelhar-se com os mais assiduos semeadores de idéas e de doutrinas.

A' semelhança de Diogo FeiJo' e de Bernardo Pereira de Vasconcellos, Octavio Mendes encontrou no trabalho o derivativo aos sofrimentos corporeos; á semelhança desses dois grandes vultos de nossa historia, chumbados, como ele, pela paralisia, a uma cadeira de rodas, pôde elevar-se tão alto, e distinguir-se tão lucidamente, que provocava a admiração dos contemporaneos, e constituia um incentivo e um exemplo a quem quer que dele se aproximasse; - era um desses homens que, pela atuação de todos os dias, aumentava o patrimonio intelectual e moral da Nação.

Por isso, de todas as lições que nos legou, a mais alta, a mais nobre, a mais inolvidavel, é a lição de sua vida mesma, padrão aos moços de nossa terra, estimulo vivo aos trabalhadores intelectuaes, que estão edificando em seus corações o Brasil de amanhã.

Nesta hora terrivel para a nossa Patria e para o mundo, em que tão necessarios se fazem os verdadeiros valores, da inteligencia e do coração, o vulto que ora tomba arrasta atrás de si uma riqueza imensa de ensinamentos morais. 
Que ele repouse tranquilo no seio da terra que tanto amou, e que o valor de seus nobres exemplos fecunde e frutifique na alma de nossa mocidade e no espirito de nossa gente!"

Por ultimo, usou da palavra o representante do corpo discente da Faculdade de Direito, o academico Henrique Brito Vianna, orador oficial do Centro Academico XI de Agosto, que pronunciou as seguintes palavras:

"Mestre! - Ao descer á terra teu corpo, já de ha muito subjugado pela fatalidade, - pela fatalidade que foi uma tortura, mas que foi tambem uma sublimação - o pensamento de teus discipulos, muito longe de mergulhar-se na descrença de teu espirito; muito longe de supôr consistisse tua existencia numa sujeição constante ás contigencias materiais, desprende-se eleva-se, edifica-se na contemplação de uma grande vida transportada nas mãos da eternidade.

E não descerá á sepultura sem que ouças os palavras daqueles a quem em vida consagraste grande parte de teu trabalho, de tuas vigilias, de tuas energias. Sim, saudoso mestre. As impressões que nos ficaram de teu luminoso magisterio na Faculdade de Direito, se se traduzem pelos conhecimentos que nos ministraste, revelam-se muito mais na elevação de nossas almas ante tua vida e nas profundas cogitações que nos sugere esse contraste admiravel entre a natureza e a liberdade. Pois foste a demonstração viva de que não é a sensibilídade requintada e total que liberta e dignifica os homens, mas, muitas vezes, a contradição mesma a que estamos submetidos de nos vermos insensibilisados e presos...

Ainda que não tivesses atingido aquele grau de estoicismo, na adversidade fisica de um Jaques Darnoux, cujo exemplo sublime alguem, muito de teu sangue, foi buscar em França como estimulo para o teu heroismo, todavia desforraste a sujeição de teu corpo em vida, enriquecendo teu espirito com o capital imenso de teu saber, difundido, para gloria do Direito patrio, nas paginas profundas de teus 
livros em beneficio da coexistencia humana e da harmonia social.

E se fosse preciso para a mocidade de hoje uma advertencia afim de que se não deixe desanimar pelo sofrimento ou pela cruz que temos chumbada em nossos hombros; se fosse preciso a tanta contradição que nos espera um exemplo humano de perseverança tão digno; se preciso ainda um estimulo vivo para o trabalho, um grande modelo de advogado, uma direção firme de honestidade profissional, aí estaria em nossa lembrança, ó mestre, tua grande existencia que se foi.

Teu passado é um titulo de gloria para S. Paulo; teu saber, uma luz a projetar-se na doutrina do Direito e na futura legislação do paiz; teu carater, uma bandeira que empunharão aqueles que te sucederão nas gerações; tua vida, essa será o drama cujo quadro teremos para sempre gravado em nossas recordações; tua catedra que abandonaste para sempre na velha Academia nós a ouviremos no percurso de nossa vida, saudosos de ti, saudosos de tua paciencia e de tua bondade. E havemos de transporta-la para muito longe, como o fazem com a tua existencia visivel as mães implacaveis do destino que, se paralisou teus passos em vida, libertou-te num só passo para a ilimitação na eternidade".

Chefe exemplar de familia, foi casado com D. Elisa de Moraes Barros, filha do senador Manuel de Moraes Barros e de D. Maria Ignez de Moraes Barros, deixando o seguintes filhos: D. Maria Ignez Mendes Pinheiro, casada com o Dr. José Martins Pinheiro Junior; D. Sylvia Mendes Cajado; D. Cecilia Mendes Mesquita, casada com o Dr. Luiz F. Mesquita; D. Elisa Mendes de Abreu, viuva do Dr. Manuel de Abreu; Dr. Octavio Mendes Filho, casado com D. Margarida Horta Mendes e D. Leonor Mendes Barros, casada com o Dr. Adhemar de Barros.

Era irmão de D. Marciana Mendes Barbosa, do Dr. Francisco Mendes, Franklin Mendes, Cassiano Mendes, Mario Mendes, D. Odila Mendes Borges, casada com o Dr. Jo- 
sé Corrêa Borges, e soror Maria do Sacramento; e cunhado dos Drs. Paulo de Moraes Barros, Antonio de Moraes Barros, Nicolau de Moraes Barros, Pedro de Moraes Barros e Jorge de Moraes Barros e das senhoras D. Anna Maria de Moraes Burchard, viuva do sr. Hermann Burchard, D. Leonor de Moraes Barros e de D. Lucia de Moraes Cardim, casada com o Dr. Mario Sergio Cardim. 